Article

\title{
Demand Side Management Studies on Distributed Energy Resources: A Survey*
}

\author{
S. Dhivya ${ }^{1}$, R. Arul ${ }^{1 *}$ \\ ${ }^{1}$ School of Electrical Engineering, Vellore Institute of Technology, Chennai 600127, India \\ * Corresponding author. E-mail address: arulphd@yahoo.co.in (R. Arul)
}

Received: 8 may 2020; Accepted: 2 june 2020; Published: 30 july 2021

\begin{abstract}
The number of distributed environmentally friendly energy sources and generators necessitates new operating methods and a power network board to preserve or even increase the efficiency and quality of the power supply. Similarly, the growth of matriculates promotes the formation of new institutional systems, in which power and power exchanges become increasingly essential. Because of how an inactive entity traditionally organizes distribution systems, the DG's connection inevitably changes the system's qualifications to which it is connected. As a consequence of the Distributed Generation, this presumption is currently legal and non-existent. This article glides on demand side management and analysis on distributed energy resources. Investigation of DSM along with zonal wise classification has been carried out in this survey. Its merits and applications are also presented.
\end{abstract}

Keywords: Demand side management, Distributed Generation, Energy

\section{Nomenclature:}

\begin{tabular}{|ll|}
\hline CCS & Carbon capture storage \\
CHP & Combined heat and power \\
DHS & Concentrating solar power \\
DG & District heating systems \\
DSM & Distributed generation \\
EMS & Demand side management \\
ESS & Energy management system \\
FBS & Energy storage system \\
HVAC & Frequency bus-signalling \\
HVDC & High voltage alternating current \\
MILP & High voltage direct current \\
PCM & Mixed integer linear programming \\
PEV & Peak current mode \\
PSO & Plug-in electric vehicle \\
PV & Particle swarm optimization \\
RES & Photovoltaic \\
SSDC & Renewable energy sources \\
SoC & Sub-synchronous damping controller \\
V2G & State of charge \\
VCM & Vehicle to grid \\
WT & Valley current mode \\
\hline
\end{tabular}

\footnotetext{
"How to cite this article: S. Dhivya, R. Arul Demand Side Management Studies on Distributed Energy Resources: A Survey. In Transactions on Energy Systems and Engineering Applications, 1(2): 1-17, 2021. DOI: 10.32397/tesea.vol2.n1.2
} 


\section{Introduction}

Due to numerous advantages, including flexibility, easy scalability, and more reliability of distributed power systems, it is gaining significant attention in recent times compared to large, centralized power systems. The paradigm of the distributed power system to be realized, potential emergence is seen in the microgrid. Local loads are provided by islanded Mode while the grid is unable, or the leading utility will swap electricity with grid-connected Mode to run microgrids as active loads, energy storage systems (ESS), other distributed generation (DG), and renewable energy sources (RES). The primary DG sources are now becoming more of RES like wind turbines (WT) systems and photovoltaic (PV) systems in recent years due to the faster expansion of power electronics. Load and RES have a short-term unbalanced power as this buffers the microgrids and makes the ESS system an indispensable element due to its intermittent nature. Summary of DG systems as it applies to different ESS technologies has been carried out in purpose evaluation and performance while the development of several ESS/hybrid RES has been carried out on previous research. Although, in this research, ESS technology capacity limitations are seldom considered. The development of procedures to predict and optimal sizing of ESS was accomplished. When the entire generation/intake is modified the ESS wishes to be redesigned, while the gadget potential is deterministic those techniques become very powerful because it avoids the over-charge/over-discharge of ESS. The charge levels of ESS and the power available in RES take into consideration by the power coordination when proposing the battery storage system and the PV systems in a synchronized regulating strategy. On a dc link, ESS integrated with PV systems is a suitable control algorithm, but a connection with the ac bus side still requires added control schemes for coordination with other distributed microgrid elements _(Peças Lopes, Soares, \& Rocha Almeida, 2011).

There is a need for a global consideration on the storage capacity of ESS and distributed RES in different power conditions and the reliable performance and flexibility of microgrids to be achieved. ESS units and DGs are coordinated by a suggested energy management system focused on model predictive control under other DG power conditions. At the same time, the voltage amplitude of microgrids and bus frequency is stabilized by some management systems microgrids derived from a coordinated SoC control strategy _(Cheng, Huang, Chien, Wu, \& Fu, 2017).

Significant technical challenges arose upon the integration of large-scale solar energy into the electric grid. To achieve power available on-demand (dispatchable power), backup power like fuelbased or energy storage is required for solar energy storage because it is an intermittent energy source. As a result of the particular falling cost in power generation in recent years, solar photovoltaic (PV) technologies are up-and-coming. Although grid reliability issues resulting from lack of storage may affect the widespread adoption of photovoltaic and its variable output, as such, falling back to using the backup source of power generation technologies like quick sloping (and regularly wasteful) topping petroleum derivative is unavoidable. As a choice to expand the matrix's unwavering quality and dispatchability, costly battery innovation might be embraced_(Hsu \& Su, 1991) .

To promptly fuse energy stockpiling, concentrating solar power (CSP) offers this particular benefit as an environmentally friendly power source. On a fundamental level, focusing solar force is a primary innovation: to produce power, heat made from a considerable measure of daylight diverted into a bit of region is changed. The working liquid is warmed; this cycle achieves CSP, otherwise called sunlight-based nuclear power. To create the ideal aftereffect of power age, the warmed liquid can be utilized with customary force age hardware like generators, turbines, and so forth. Nuclear power stockpiling can readily acknowledge and store heat. This makes minimal expense energy stockpiling plausible, for example, the utilization of solar warmth as a fuel source in CSP, and requests warming of capacity materials and lodging it in a protection tank. Correcting hybridization is an additional benefit of CSP. It can, without much of a stretch, be consolidated with another fuel source because of the traditional force age gear that adjusts CSP notwithstanding the nuclear power assortment, these manufactured ways incorporate the accompanying:

- Synergies between advances upgraded by plan and activity improvement.

- Opportunity for adaptable activity 
- Increase in dependability and Increase in capacity utilization of power generation equipment

- Expansion in dispatchability by consolidating environmentally friendly power with dispatchable energy

- Decrease capital expense by dividing hardware among numerous fuel sources.

At or below 450ppm is the benchmark required to stabilize the concentration of carbon dioxide $\left(\mathrm{CO}_{2}\right)$ in the atmosphere to prevent potential disaster on climate change with high likelihood; this is by an intergovernmental panel on climate change. To accomplish this, it is required that by 2100 and beyond, global $\mathrm{CO}_{2}$ emission must be eliminated by $100 \%$, while it is estimated that by about 2075 , the $100 \%$ reduction should be achieved, and by 2050 it should be reduced by $50 \%$ of the global emission of 2006. Removal of $\mathrm{CO}_{2}$ from the air and little or no $\mathrm{CO}_{2}$ generation from the industries help accomplish this. The final energy demands are provided by a significant fraction of electric power, which is likely to increase over time. To that end, carbon-neutral manner or low carbon reliable electricity must be provided in a considerable quantity _(Zhu, Tang, Lambotharan, Chin, \& Fan, 2012).

This review article is organized as follows: Section 2 explains different technologies for renewable sources and storage. Section 3 discusses about the DSM evolution on RES. Section 4 describes zonal classification of DSM. Section 5 enlists the essence of DSM with its modelling in Section 6. Its merits and applications are showcased in Section 7 and 8 respectively. Future scope is highlighted in Section 9.

\section{Technologies for sources and storage}

There are three classes low carbon electricity technology fall into, it includes: (1) in a technique referred to as Carbon [Dioxide] Capture and storage (CCS); in a deep sedimentary basin, captured $\mathrm{CO}_{2}$ is produced earlier than it's miles vented and injected makes use of fossil fuels as a number one electricity source or replaced fossil-fuel electricity generation (2) nuclear fission (3) "renewable" sources. Here we can focus on the choice between the two, but these three categories are where decisions regarding actual technology deployment portfolios entail. It was explicitly contrasted Concentrated Solar Power (CSP) with coal-fired electricity production coupled with CCS. The contrast and other recent investigations say that coal-fired power with CCS and CSP are among the only sustainable alternatives that can provide entirely dispatchable electricity. Many both technologies are suggested to be incorporated together in future energy systems, so reports many analysts. Unfortunately, political support and funding are greatly needed for these technologies to grow to compete. Due to significantly different industrial lobbies behind them, it might increase the competition from the political perspective. Earlier on, the support to which each technology receives: when cost and performance are compared, the technology's position improved because investment in technology should produce technological studies and declining prices. It is priceless to examine the potential choices between them in isolation aid in a different understanding of the technologies_(Sheikhi A. , Rayati, Bahrami, \& Ranjbar, 2015).

The turbine is driven by the steam produced from heat generated from direct sunlight tap by the CSP plants to generate electricity. Sunlight is concentrated into one focal line by mirrors to achieve high steam temperatures or a focal point. The most mature CSP technology currently, called the parabolic trough CSP station, uses the focal line of the mirror through an absorber tube to concentrate sunlight with a curved mirror. In the central tower receiver into one point, thousands of flat mirrors are used to focus sunlight, as used by solar tower technology. Although relatively new, solar tower technology produces higher conversion efficiencies due to its higher steam temperature. Only at laboratory scales, other concentration technologies been tested, such as Dish sterling and Fresnel concentration technologies _(Sheikhi, Bahrami, \& Ranjbar, An autonomous demand response program for electricity and natural gas networks in smart energy hubs, 2015).

Thermal energy storage can be incorporated with CSP technologies. In a corporation like this, the turbine is powered by part of the heat that has been generated and then diverted to a storage facility at a letter time while the rest of the heat is transformed to electricity automatically. The turbine cycle consumes virtually all of the gathered heat. Therefore the thermal storage units are 
pretty efficient. For 24 consecutive hours for the first time, in July 2011, the Gema solar power tower was used to generate electricity. It is equipped with $15 \mathrm{hrs}$ of storage, but generally, the CSP station was built in Spain incorporates thermal storage. Compared to the most fossil-fuel power plant, the Gema solar power tower plant is relied upon to arrive at a yearly limit factor of $80-85 \%$. On a leveling the cost basis, the increased capacity factor balanced even more than the higher investment even though the storage increases the total investment cost. As the availability of the station increases, the average storage utilization decreases as a result of modern technology expanding up to $13 \mathrm{~h}$ of storage tenderly increased the Levelized cost. Longer storage time prevented by technical barriers, cheaper and larger storage is getting the attention of recent researcher examination and development do not appear to concern storage time. The underutilization of power in summer from a solar station translates to its increased reliability during winter, but an estimate shows that a solar plant with ample storage of about $416 \mathrm{hr}$ could serve the entire year facilitating base-load power production. In a hybrid solar-fossil power station, fossil fuel complements solar concentration.

\section{Evolution of Demand Side Management (DSM) in Distributed Energy Resources}

In a high direct normal insolation, like arid areas and desert CSP, it is recommended only to direct sunlight. Mexico, the southwestern United States, and Northern Africa's desert are all important regions where CSP can be used to provide enough energy to demand centres in Europe and North America. HVDC (high-voltage direct current) transmission lines will link these demands and supplies at a low cost. HVAC (high-voltage alternating current) lines lose less than half of a regular full-load HVDC grid, losing 2-3\% of full-load transmission per $1000 \mathrm{~km}$. More than $100 \mathrm{GW}$ of HVDC transmission lines have been deployed on all continents for more than seven decades, so there is much familiarity with HVDC transmission lines.

Location, solar collector technology selected, hybrid plant configuration, hybrid energy source, and many others are considered when realizing the benefit. When choosing the best technologies for hybridization, technical feasibility and economic play a significant role. A hybrid energy source is classified with CSP hybrid systems by synergies. When significant parts and gear, for example, steam turbine, are shared and associated indeed by two frameworks, the happening cooperative energies are called medium mixture. To create power for the medium and light synergistic framework, the half and half host assume a more massive part as the CSP segment assumes a minor part and can't run without the host, while the CSP innovation nonattendance doesn't influence the activity of the crossover to have. Supplemental pretends solar warming as commonly this framework has a low sunlight based offer. CSP part is more vital to plant activity in firmly synergistic half and half as there has a higher solar offer and offers significant gear.

CSP-biomass, on the other hand, are a recognized alternative for low-cost base load/dispatchable renewable energy. However, thinking about its biomass assets and the restricted location with excessive direct regular irradiance makes it a spot market. Countries with the area that meets both criteria can comfortably undertake such projects; these countries include but are not limited to, are Brazil, India, Thailand, Greece, Italy, Spain, Australia, amongst others. Considering the economic reality of getting money for such projects, it is crucial to maximizing efficient biomass and commercial viability as efficiently as possible.

To make complementary competing energy technologies, hybridization can make this possible. Careful consideration of the environmental and economic benefits of the proposed system and the technical feasibility is necessary for realizing the full benefits of hybridization. A thorough analysis is needed to get an overview of the advantages and disadvantages of CSP discussed and possible hybrid configurations and to feature the distinctive fuel sources with which CSP might be hybridized. Wind energy, solar PV, geothermal energy, biofuels, natural gas, and coal are the energy sources.

In the 1980s, a brief investigation and proposal to combine CSP with biomass/waste materials using dish systems was created. No stations were built due to financial and technical constraints. Thermal oil with the mature trough technologies was used in the station is located further north in Spain were no other CSP plant. At 520C the biomass boilers superheat the steam, and at 40 bar, the solar field generates saturated steam. To avoid high-temperature corrosion at the superheaters 
caused by this kind of combustion, the steam temperature is carefully chosen. Greater than 40 bar can the steam pressure be raised for the concept to be further optimized.

Several studies have examined the hybridization of parabolic trough plants with biomass. Consideration of biomass, molten salt cycle, or thermal is what this research is about and integrating biomass fire steam boilers into the CSP station's water-steam cycle. Also, alternative waste materials and biomass with hybridization have been examined from the Fresnel system. Fresnel can steam up to $500^{\circ} \mathrm{C}$ temperature, and that is the advantage of using Fresnel and other conversion efficiencies that are higher. Unfortunately, CSP configuration does not have any conversion plant in existence yet.

Volumetric air receivers used solar towers, an example of biomass combined with molten salts, and direct steam generation with solar towers are currently undergoing investigation. Because of the extreme complexity of any such system and the confined reference scenario of excessivetemperature air tower equipment, Solar towers are expected to be easier to fund with DSG or molded salts. Integrated Gasification, which combines biomass with high-temperature air systems, is the second option, in accordance with the CSP, is to heat the compressor to $800^{\circ} \mathrm{C}$ and combusted syngas, similar to the SOLGATE project, to raise the temperature up to $1150^{\circ} \mathrm{C}$, but to use biomassderived syngas rather than natural gas. To make such an operation very efficient Rankine cycle is operated with the use of gas turbine exhaust. It is not considered because each technology has no longer been examined at business scale additionally impossible to stabilize finance to execute this type of hybrid concept.

There are many benefits of coal with solar thermal power hybridization. It is an energy source that is a low-cost, prevalent, and abundant natural resource. Coal can be altered with supplemental solar, nuclear power; these present numerous chances. Evacuation of $\mathrm{CO}_{2}$ in post-burning dissolvable recovery, boilers air pre-warming, direct steam age, pre-warming, and boilers feed waters are the different solar warmth infusion focuses made accessible in a coal power station. The overall $\mathrm{CO}_{2}$ emissions on the station are removed by the solar thermal energy, while the coal ensures power reliability by providing a dispatchable fuel source. One source indicates that over $25 \%$ more electricity is generated from a hybrid station than a stand-alone solar plant, and only $72 \%$ of its cost is used, showing that hybridization can reduce the overall CSP station cost.

The cooling water quantity increases by $10-20 \%$ when CCS is added for integrating Gasification attached with Cycle facilities, and for supercritical and subcritical pulverized coal facility, it rises up to $120 \%$. At some locations, the feasibility of coal power with CSS might be reduced by these water requirements. However, coal may be transported to electricity plant life at certified sites, so stock water availability will not likely end up a prime challenge.

Dedicated to the CCS project, it became over \$26 billion in April 2010 to use authorities earth extensive for its support, resulting from government-enterprise collaborations, so eighty large-scale commercial tasks were of their numerous tiers of improvement. An estimate of garage ability varies widely, so geographic garage ability is, in the long run, a main constrain the progress within the scale of CCS. Worldwide geographic formulations in line with professional stakeholder's opinion envisioned a technical capacity of $200 \mathrm{GtCO}_{2}$ of storage capacity, this estimation might be affected, and the technical potential may be significantly smaller in the final volume of proven storage reserves due to consideration of economic, technical and spatial factors may reduce this potential. However, viable storage is still likely to be very large. Possible storage capacity might further be decreased by hydraulic fracturing. Given the current economic environment, the world coal reserve is expected to run for at least the next 100 years, so there is likely a good storage site to handle CCS operations within this time frame.

\section{Different zones of analyzing DSM}

\subsection{Consumer based DSM}

The sharp surroundings of every domestic entail achievable pressure shape, personal power storing contraptions, bidirectional charging/handing over plug-in electric vehicle (PEV), and adroit meter with stepped forward correspondence techniques. Each home is outfitted with a photovoltaic type, power-saving gadgets, and an optional PEV with Vehicle to Grid (V2G) construction, and the 
energy can be supplied at any point from the utility organization, amassing appliances, or PEVs battery, anticipating that the solar energy is used once it is available.

Our machine decides the source from which power can be supplied, and the most important practical movement of the batteries is concerned with the reserving result. Before gambling out our phone, we will have every occupant's house interest profile, which consolidates identity, schedulability, assisted variety for execution, and the beginning period internal a day off per interest at the profile. For PEV, we'll need the engine's standard use profile, which compiles the primary statistics of an electric vehicle, the timeframes in which the vehicle arrives at/leaves the business house, and its state of charge (SOC) during the appearance/flight.

Overall, we obtain the registered energy age facts from the PV shape and then used them for estimating the energy age of a day using the auto-regressive assessment approach, in which the generated solar ordered energy age profile contains the hourly energy age facts during the day. Other than the three wellsprings of statistics simply mentioned, the tremendous assessing profile is the fourth dedication to our machine. To decrease the computational time for such a complicated issue, the particle swarm optimisation (PSO) is widespread that's remembered for instant estimation and coming to transport towards the perfect result.

The first one is the hidden configuration so that it randomly supply debris first, and sometime later package deal debris into different stages reliant upon their contrasting pressure cost, and finally pick a few middles of the waste in every stage because of the primary atom. Doing so ensures the debris is given additional impartially streamed throughout the pursue region and is free of getting caught at neighboring optima. The resulting creation is the affiliation measure, in which the fitness well worth would in like way be evident since the cease version to cease the loop if the fitness was well worth of each atom all movements near.

Near the end, our computer generates four yields, with an exciting plan, a battery plan, a PEV battery timetable, and an energy promotion plan. The flowchart of DSM estimation is seen in Fig. 1.

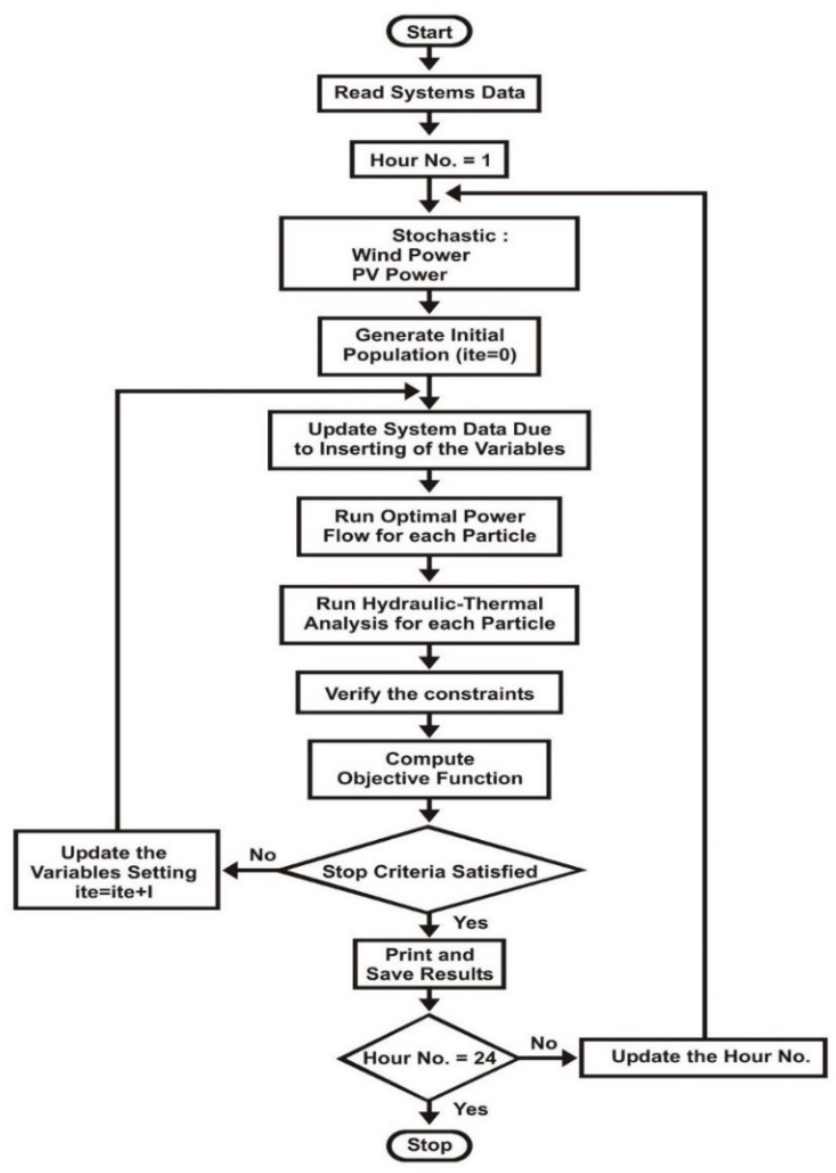

Fig.1 Flowchart of DSM through PSO 


\subsection{Domestic purpose DSM}

The surroundings of each residence are unknown, and all of the dynamic PEVs may be linked collectively as a power-sharing network with an aggregator. Every PEV can be operated with the assistance of the aggregator; additionally, for simplicity, only one motion (charge/discharge) can be dispatched reliably (fig. 2). To keep away from the safety issue, procedures are executed. Introductory, a dispersed machine is tried to make sure every domestic can end its smoothing out domestically without revealing pressure use to others; the solitary open statistics with the aid of using huge society is the outright energy use of the community. Second, the aggregator is stuffed because the vital commercial enterprise region permits every domestic to shop for and promote its PEVs power. The naked critical strategies depicting how PEVs' motion is managed and how statistics are moved amongst houses are mentioned within the accompanying region. The community is a stage PSO becoming a member of a form of recreation speculation. The first stage executes the scattered best recreation thru which every domestic play out its personal DSM even as inspecting regular benefit. With the assistance of "stable complete computation", each player can skip round the overall community load statistics from others without understanding others energy use profile and a brief time later performs out its DSM even as thinking about a community well worth as normal benefit. By then, the resulting stage plays sharing power allocator, in which the aggregator receives the feasible sharing general from all inhabitant houses first, and after that invigorates the power mission to every domestic in the course of every good crosscut day. While the occupants inside the first stage endeavor to attain their locations in every round, the splitting affiliation inside the resulting stage grades by gadgets consistent.

\subsection{Commercial DSM}

Like the previous challenge shifts to viable company assembly, the business takes the central role of providing all of the PEVs and generating electricity. It suggested a PEV preventing territory Chairman between a traditional parking type and a house. In this case, regulator leads the center organizing degree and blends data, approximately energy load facts, and PEV organizational decision. Where there is a PEV that seems to be stuck in place, the regulator initiates the smoothing out cycle and chooses the new technique. The regulator is ordered ward at the description of Target Charging affiliation. In the wake of the social event all of the essential facts, regulator begins off evolved the smoothing out cooperation the use of PSO resolved to decrease the general pressure cost. Specifically, while the day begins off, regulator selects out the motion agenda of PEVs battery and preserves down to test whether or not the surroundings have any change. Soon after a PEV essentially seems to prevent location or simply leaves, the regulator invigorates the PEVs facts and reschedules with the brand new facts status. Like this, the agenda could be modified via way of means of this designing while the surroundings review a few changes (fig. 3).

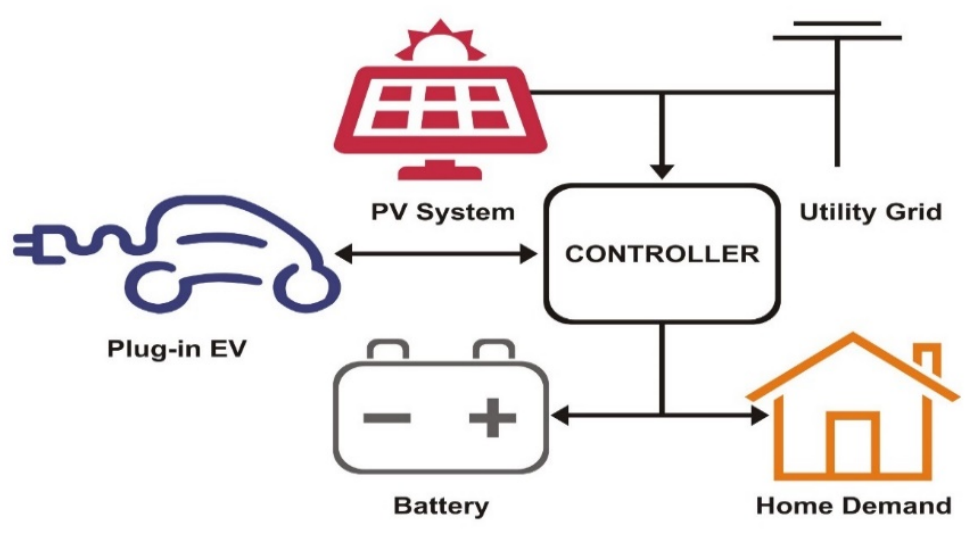

Fig. 2. Configuration of Domestic DSM 


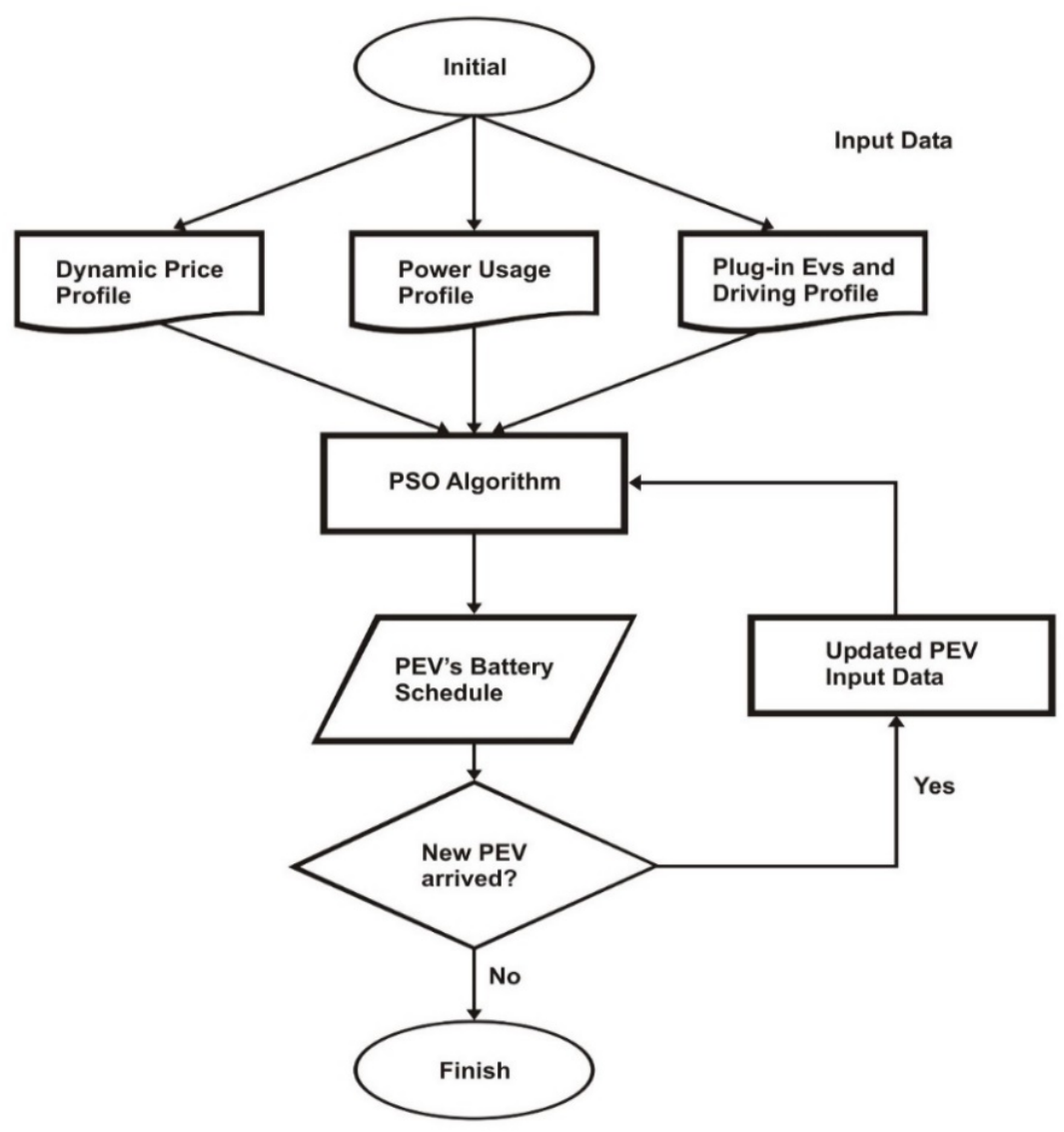

Fig. 3: Flow chart of the DSM for commercial purposes

\section{Need of DSM for Distributed energy resources:}

Sub-synchronous damping controller (SSDC) based Power Management Scheme is retaining the droop characteristic of valley current mode (VCM) autonomy in power-sharing. An additional benefit of using frequency bus-signalling (FBS) is to accomplish reorganized control management. FBS implies the use of bus frequency thresholds control to activate mode fluctuations. The orderly operation of ESS and RES units can be categorized into various modes. The forthcoming paragraphs are shown for the four working modes:

- Mode I: The islanded microgrid is in regular operation in this control mode, and not all ESS is fully charged. In order to carry out grid creation, at least one ESS must be handled in VCM. The storage system's total control capability is unbalanced between generation and usage. Both RES units run in peak current mode (PCM) and provide adequate power to the system.

- Mode II: Since all ESS units are finally charged in this control mode, they are all regulated in PCM to reduce charging power. We infer that there is no modern communication system for instructing RES to change modes, so the RES units remain in PCM mode. As a part of this control mode, the bus frequency for all PCM-based systems rises as the system's overall power supply approaches demand.

- Mode III: The RES units operate in VCM as grid-forming units in this control mode, while the ESS units are regulated in PCM to limit capacity. As the bus frequency approaches the up-threshold up, which should be installed under the total frequency variance as specified in various grid codes, the RES Mode is changed from PCM to VCM.

- Mode IV: During this mode of operation, the ESS units convert to VCM and collaborate with the RES to manage load power use. As the bus frequency dropped below a certain threshold, the ESS mode shifts from PCM to VCM, just as it does in Mode III. The power output is less than the power input in this situation, and the ESS units appear to discharge. 
The Modes I and III are static modes in a scheme that dominate primary functions, while Modes II and IV are dynamic modes that allow switching between Modes I and III by executing FBS. The approach begins in Mode I, with the droop slopes of the ESS and RES curves set to constant and infinity, respectively.

\section{Various Models of DSM}

Resiliency in strength structures is defined because of the capacity of the strength gadget to undertake and face up to low-opportunity extreme effect events. Because of their islanding capacity and potential to sustain renewables penetration, microgrids are regarded as a realistic strategy to boost the resiliency of control systems. To use microgrids as an advantage of immoderate efficiency, they need to be equipped for specific incidents. Therefore, analogous to the resilience improvement approach suggested, proper right here is broken up into stages. A constructive scheduling model, in the first step, ensures practical islanding and critical mass survival after any major fault event for $\mathrm{n}$ consecutive cycles. The survivability of groups within an islanded duration is regarded in the second stage by defining the precedent between battery charging and feeding of non-critical masses. Furthermore, in order to avoid undue load shedding, dynamic penalty costs for critical and noncritical masses are carried_(Kinhekar, Padhy, \& Gupta, 2014).

\subsection{Proactive Operation Model}

The proactive operating framework is completed prior to the incident, i.e., within the path of grid-connected Mode. Except for the averaging and cumulative results, this model considers a 24hour forecast horizon, with a sampling time of 1 minute. An case in this sample refers to the most significant outage, which is most often triggered by natural disasters. Hurricanes, tsunamis, high winds, floods, heavy rainfall, and other severe weather events have caused some of the most serious outages in recent years. Climate change is expected to increase the pace and length of these sports in the near future. This study's resilience-oriented utility scheme specializes in extreme weather sports. Resilience-oriented service systems are traditional, resulting in lower running costs. As a result, specific programs are discouraged from being used at such times. In the case of inclement weather sports, preliminary warnings are issued using the method of community meteorological agencies. The suggested preventive operating scheme was triggered as quickly since the initial alerts are released. As the base model of the proposed operating structure for resilience is identical, this research _(Logenthiran, Srinivasan, \& Shun, 2012) builds the best compact version for all microgrid components for comprehensive mathematical simulation.

\subsection{Survivability-Oriented Operation Model}

After an incident, i.e. in Island Mode, the survivability-focused operating system is applied. The operational horizon during an emergency is from the time of the incident until the end of the day. The fragility curve statistics of the relevant parameter(s) representing the occurrence can be used to approximate the case length. However, due to the focus of this have research on learning the limits of EMS, the event time is the thinking of being remembered in this have research. The operating model's goal is to maximize the survival of strength provided to loads, especially critical loads.

This index of resilience attempts to assess the microgrid's average total efficiency in the face of fantastic scenarios. This requires the management of character, the interconnected process of the microgrid and the hardware look at the interconnected case of the microgrid. In general, methods for resolving optimization problems are entirely based on finding a position and target function. Linear Programming is a highly effective method for solving a specific intent feature situation with linear equality or inequality constraints. Non-linear Programming, on the other hand, is aimed at solving non-linear purpose abilities and restrictions. Stochastic Programming is a suitable approach that uses possibility distributions of multiple variables to solve problems that require confusion. Computational intelligence approaches such as the Genetic Algorithm and Particle Swarm Optimization have been anticipated to evaluate the world's best solutions, albeit at the cost of 
needless computational effort. The choice of a few of the alternatives mentioned above is related to the trade-off between precision and processing time. Non-linear mechanisms in a microgrid, such as wind power, solar energy, batteries, power stations, digital power devices, and so on, tend to be the top qualified for addressing actual embedded microgrid problems. It is possible to list the issues and literature analysis of optimization solution packages for microgrids.

While non-linear models give more excellent representation, and linearised models are routinely seen to minimize computing effort. Linearization of dispatchable generators, loss-free or linear power transmission losses, continuous charge/unloading of power storage component reliability, and linear conversion losses are all considered to be equal to EMS formulation. Due to the objective of this research to show and measure the effect on the resilience of natural microgrids of low fidelity models, the linear model is considered. A Mixed integer linear programming (MILP) is carefully chosen and we have seen the IBM CPLEX financial solver. The drawbacks are, for that purpose, discovered through experimental measurements whereby non-linearities of the natural microgrid components are inherited_(Liu, Yuen, Huang, Hassan, \& Wang, 2014). Table 1 enlightens different programming techniques with its features.

Table 1: Different techniques prevailing in literature for EMS

\begin{tabular}{|c|c|c|c|c|c|}
\hline $\begin{array}{l}\text { EMS } \\
\text { Type }\end{array}$ & $\begin{array}{c}\text { Optimization } \\
\text { Objective }\end{array}$ & $\begin{array}{l}\text { Optimization } \\
\text { Algorithm }\end{array}$ & $\begin{array}{c}\text { Major } \\
\text { Consideration }\end{array}$ & Ref & Limitations \\
\hline \multirow{3}{*}{ Centralized } & $\begin{array}{c}\text { Cost } \\
\text { minimization }\end{array}$ & $\begin{array}{c}\text { Particle } \\
\text { swarm } \\
\text { optimization }\end{array}$ & $\begin{array}{c}\text { 1.Uncertainties in } \\
\text { load and renewable } \\
\text { power } \\
\text { 2.Grid-connected } \\
\text { mode only }\end{array}$ & $\begin{array}{c}\text { (Nikmehr \& } \\
\text { Ravadanegh, } \\
\text { Optimal Power } \\
\text { Dispatch of Multi- } \\
\text { Microgrids at } \\
\text { Future Smart } \\
\text { Distribution Grids, } \\
\text { 2015) }\end{array}$ & \multirow{3}{*}{$\begin{array}{l}\text { 1. Increase in } \\
\text { computational } \\
\text { burden of central } \\
\text { EMS } \\
\text { 2. Failure to } \\
\text { preserve customer } \\
\text { privacy of } \\
\text { microgrids } \\
\text { 3. Requirement of } \\
\text { extensive } \\
\text { communication } \\
\text { setup }\end{array}$} \\
\hline & \begin{tabular}{l}
\multicolumn{1}{c}{ Cost } \\
minimization \\
and reliability \\
maximization
\end{tabular} & $\begin{array}{l}\text { Imperialistic } \\
\text { competitive } \\
\text { algorithm }\end{array}$ & $\begin{array}{l}\text { 1.Load-generation } \\
\text { uncertainties } \\
\text { 2.Both gird- } \\
\text { connected and } \\
\text { islanded modes }\end{array}$ & $\begin{array}{c}\text { (Nikmehr \& } \\
\text { Ravadanegh, } \\
\text { Reliability } \\
\text { evaluation of } \\
\text { multi-microgrids } \\
\text { considering } \\
\text { optimal operation } \\
\text { of small scale } \\
\text { energy zones } \\
\text { under load- } \\
\text { generation } \\
\text { uncertainties, } \\
\text { 2016) }\end{array}$ & \\
\hline & $\begin{array}{c}\text { System } \\
\text { Reliability } \\
\text { maximization }\end{array}$ & \multirow{2}{*}{$\begin{array}{c}\text { Mixed } \\
\text { integer linear } \\
\text { programming } \\
\text { (MILP) }\end{array}$} & $\begin{array}{l}\text { 1.Detalled modeling } \\
\text { of unbalanced } \\
\text { systems } \\
\text { 2.Islanded mode } \\
\text { only }\end{array}$ & $\begin{array}{c}\text {-(Olivares, } \\
\text { Cañizares, \& } \\
\text { Kazerani, 2014) }\end{array}$ & \\
\hline \multirow{2}{*}{$\begin{array}{l}\text { Centralized } \\
\text { With } \\
\text { Sequential } \\
\text { operation }\end{array}$} & $\begin{array}{c}\text { Cost } \\
\text { minimization }\end{array}$ & & $\begin{array}{l}\text { 1.Distribution of } \\
\text { computational } \\
\text { burden } \\
\text { 2.Grid-connected } \\
\text { mode only }\end{array}$ & $\begin{array}{l}\text { (Song, Lee, Kim, } \\
\text { Im, \& Lee, 2015) }\end{array}$ & \multirow{2}{*}{$\begin{array}{l}\text { 1.Failure to } \\
\text { preserve privacy } \\
\text { of microgrids } \\
\text { 2. Requirement of } \\
\text { extensive } \\
\text { communication } \\
\text { setup }\end{array}$} \\
\hline & $\begin{array}{c}\text { Cost } \\
\text { minimization }\end{array}$ & $\begin{array}{c}\text { Sequential } \\
\text { quadratic } \\
\text { programming }\end{array}$ & $\begin{array}{l}\text { 1.demand bidding } \\
\text { and three level } \\
\text { control } \\
\text { 2.Grid- connected } \\
\text { mode only }\end{array}$ & $\begin{array}{c}\text { (Tsikalakis \& } \\
\text { Hatziargyriou, } \\
\text { 2011) }\end{array}$ & \\
\hline Decentralized & $\begin{array}{c}\text { Cost } \\
\text { minimization }\end{array}$ & $\begin{array}{c}\text { Multi-agent } \\
\text { system with } \\
\text { contract net } \\
\text { protocol }\end{array}$ & $\begin{array}{l}\text { 1.Autonomous } \\
\text { operation and } \\
\text { customer privacy }\end{array}$ & $\begin{array}{c}\text { (Kim, Lim, \& } \\
\text { Kinoshita, An } \\
\text { Intelligent } \\
\text { Multiagent System } \\
\text { for Autonomous } \\
\text { Microgrid } \\
\text { Operation, 2012) }\end{array}$ & $\begin{array}{l}\text { 1. Unawareness of } \\
\text { system level } \\
\text { resources } \\
2 . \text { Due to } \\
\text { individual } \\
\text { objectives, } \\
\text { equilibrium may }\end{array}$ \\
\hline
\end{tabular}




\begin{tabular}{|c|c|c|c|c|c|}
\hline & $\begin{array}{l}\text { Minimization of } \\
\text { load shedding }\end{array}$ & & $\begin{array}{c}\text { 1.Competitive } \\
\text { environment among } \\
\text { suppliers } \\
\text { 2.Islanded mode } \\
\text { only }\end{array}$ & $\begin{array}{c}\text { (Kim, Kinoshita, } \\
\text { \& Shin, A } \\
\text { Multiagent System } \\
\text { for Autonomous } \\
\text { Operation of } \\
\text { Islanded } \\
\text { Microgrids Based } \\
\text { on a Power } \\
\text { Market } \\
\text { Environment, } \\
\text { 2010) }\end{array}$ & $\begin{array}{l}\text { exist and further } \\
\text { optimization may } \\
\text { not be possible }\end{array}$ \\
\hline & $\begin{array}{l}\text { Cost } \\
\text { minimization } \\
\text { and reliability } \\
\text { maximization }\end{array}$ & $\begin{array}{c}\text { Stochastic } \\
\text { optimization }\end{array}$ & $\begin{array}{c}\text { 1.2-layered } \\
\text { stochastic model } \\
\text { and uncertainties } \\
\text { 2.Both grid- } \\
\text { connected and } \\
\text { islanded modes }\end{array}$ & $\begin{array}{c}\text { (Wang, Chen, } \\
\text { Wang, \& kim, } \\
\text { Decentralized } \\
\text { Energy } \\
\text { Management } \\
\text { System for } \\
\text { Networked } \\
\text { Microgrids in } \\
\text { Grid-Connected } \\
\text { and Islanded } \\
\text { Modes, 2016) } \\
\end{array}$ & \\
\hline & $\begin{array}{l}\text { Supply adequate } \\
\text { maximization }\end{array}$ & $\begin{array}{l}\text { Average } \\
\text { consensus } \\
\text { algorithm }\end{array}$ & $\begin{array}{l}\text { 1.Self-healing and } \\
\text { autonomous } \\
\text { operation } \\
\text { 2.Both grid- } \\
\text { connected and } \\
\text { islanded modes }\end{array}$ & $\begin{array}{c}\text { (Wang, Chen, } \\
\text { Wang, \& Chen, } \\
\text { Networked } \\
\text { Microgrids for } \\
\text { Self-Healing } \\
\text { Power Systems, } \\
\text { 2016) } \\
\end{array}$ & \\
\hline \multirow{4}{*}{ Hybrid } & $\begin{array}{l}\text { Cost } \\
\text { minimization } \\
\text { and reliability } \\
\text { maximization }\end{array}$ & \multirow{4}{*}{ MILP } & $\begin{array}{l}\text { 1.Three-level control } \\
\text { and dynamic } \\
\text { conditions } \\
\text { 2.Both grid- } \\
\text { connected and } \\
\text { islanded modes } \\
\end{array}$ & $\begin{array}{c}\text { (Zhang, Zhao, \& } \\
\text { Hong, 2015) }\end{array}$ & \multirow{4}{*}{$\begin{array}{l}\text { 1. Parallel } \\
\text { operation of } \\
\text { microgrids } \\
\text { 2. Single-level } \\
\text { privacy of } \\
\text { customers, easy to } \\
\text { reveal } \\
\text { 3. Reduction in } \\
\text { resiliency of } \\
\text { disconnected } \\
\text { microgrids } \\
\text { 4. Central EMS } \\
\text { failure results in } \\
\text { autonomous } \\
\text { operation }\end{array}$} \\
\hline & $\begin{array}{c}\text { Cost } \\
\text { Minimization }\end{array}$ & & $\begin{array}{l}\text { 1.Control of voltage, } \\
\text { frequency, and } \\
\text { power } \\
\text { 2. Both grid- } \\
\text { connected and } \\
\text { islanded modes } \\
\end{array}$ & $\begin{array}{c}\text { (Tian, Xiao, } \\
\text { Wang, \& Ruoxing, } \\
\text { 2016) }\end{array}$ & \\
\hline & $\begin{array}{l}\text { Cost } \\
\text { minimization } \\
\text { and reliability } \\
\text { maximization }\end{array}$ & & $\begin{array}{l}\text { 1.Hybrid microgrids } \\
\text { and diversity gain } \\
\text { 2.Both grid- } \\
\text { connected and } \\
\text { islanded modes }\end{array}$ & $\begin{array}{c}\text { (Che, } \\
\text { Shahidehpour, } \\
\text { Alabdulwahab, \& } \\
\text { Al-Turki, 2015) }\end{array}$ & \\
\hline & $\begin{array}{c}\text { Cost } \\
\text { Minimization }\end{array}$ & & $\begin{array}{l}\text { 1. Load smothering } \\
\text { and cooperative } \\
\text { operation } \\
\text { 2.Islanded mode } \\
\text { only } \\
\end{array}$ & $\begin{array}{l}\text {-(Wang, Mao, \& } \\
\text { Nelms, 2015) }\end{array}$ & \\
\hline
\end{tabular}

\section{Merits of DSM}

DSM is a technique that can result in cost-effective, financial savings for microgrid energy users by minimising their electricity use, such as moving energy usage from peak to off-peak hours. Unanticipated time-shifting in an age or load, on the other hand, may have negative effects in terms of power cost, and even worse, a brownout in an electrical power supply grid, due to the reasons described in the preceding paragraphs. Though negligible in the short run, the long-term effect may be immense_(Ogwumike, Short, \& Denai, 2015) _(Zhang, Chen, Su, Dong, \& Li, 2014).

Electric power systems and district heating systems (DHS) are coordinated using the economic dispatch process. As a result, a consolidated dispatch model for a networked electricity system with electrical and thermal energy sources is proposed. Heat storage tanks and DHS are used to increase the operational stability of combined heat and power (CHP) systems (due to their ability to adjust the internal water temperature at a lower cost). The DHS's two main components are heat sources (CHP units and heat storage tanks) and heat supply subsystems. Heat is supplied to DHS in the 
form of hot water or steam through transmission pipelines (supply and return pipes) and distributed to end-users. The Newton-Raphson procedure simulates the hydraulic and thermal integration of two models for measuring mass (tubes) flow rates inside each tube and the return distribution temperatures of each DHS node _(Sheikhi, Rayati, \& Ranjbar, 2016) _(Kuo, y otros, 2016).

As energy revolution in recent years has rapidly evolved, the DG reasserts in the microgrid have become central to RES, including photovoltaic (PV) and wind energy turbine (WT) architectures. On the other hand, ESS frameworks are critical components of a microgrid because, Owing to their transient design, they buffer the short-term unbalanced energy between RES and load. Several hybrid RES/ESS architectures have been developed in previous research, and the overall efficiency and logic assessment of different ESS innovations implemented in DG structures is presented. The chance of ESS, on the other hand, is barely mentioned in those novels. As a result, methodologies for forecasting and sizing ESS have emerged. When the device capability is deterministic, specific approaches are important for minimizing ESS over-charge/over-discharge, but the total energy generation/intake varies. Any of them is considered to have energy in RES and situation of SoC conditions of ESS, in which a coordinated exploitation strategy for PV systems and battery storage machines is applied. This software modifies a set of rules for PV systems with embedded ESS on a direct current link. However, to connect with the various distributed microgrid variables attached to the ac bus side, an additional manipulation scheme is needed _(Turker, Hably, \& Bacha, 2013) _(Nguyen \& Le, 2014).

\section{Applications of DSM}

Many types of management frameworks and computations are performed within the authored works in the DSM system area. The vast majority of them employ complex programming or direct programming abilities, which are common strategies for achieving outstanding solutions for streamlining complexity. In any case, they cannot cope with big scope trouble because of calculation limits. Additionally, multiple works likewise recall the flammable fuel line community inside the deliberate DSM structure, but the proposed paintings hope to cope with the DSM trouble in complicated situations thinking about electricity sharing arrangement_(Zou, Qian, Attia, \& Xie, 2012). To lessen the processing load and openly broaden the issue scale, specialists currently utilize transformative or heuristic calculations, Game hypotheses, and Artificial intelligence as the arrangement_(Kamal, Assi, Maier, \& Uddin, 2014). Alluding to the examination made by these calculations have a significant and valuable property which is not difficult to figure and can be reached out to a case with an enormous size of gadgets and examples. Be that as it may, without an assortment of tremendous information measures, the AI procedures can scarcely be used because of the challenging combination of the preparation stage. Thus, we choose to utilize the heuristic calculation, to settle the action booking just as charging/releasing issues. Other than different estimations, there is a continuously increasing wide variety of research thinking about the PEVs charging plan, in which the first assignment is to lower the Standard well worth and the pressure price impelled through the significant electric powered strength demand. Of late, PEVs battery development has been stepped forward, so it now no longer can save huge share of pressure manage and supply again to a grid with the assist of V2G method while required, whose pile transferring restriction can assist enhancing the number one DSM shape. Regardless, they recall the unmarried domestic development with PEV charging plan difficulty but couldn't expand the close to research to a community out and decline the available pressure price _(Moghaddam Arani \& I. Mohamed, 2018)_(Hasib, Nikitin, \& Natvig, 2014).

Of course, given the confined figuring strength, examiners can virtually carry out reserving with PEV and conceivable pressure or electricity promoting restriction. The proposed paintings take PEVs battery motion, conceivable pressure input, electricity imparting to a framework, and pastime primarily based reserving (in preference to controlling machines) into notion to skip at the DSM in the solitary domestic interior a community. Also, every residence is provided with a touch battery as non-public electricity storage. With the significant difficulties demonstrating and the assistance of swift computing, the planned paintings are finally sufficient to deal with an astute domestic. Past the man or woman domestic smoothing out task, the problem has contacted the community. While 
the degree of PEV provides, selecting the correct way of the PEVs charging period to extrude the general intensity loading and minimize the price and Standard is the primary goal of, apart from the group constraint is yet to be taken care of. All matters considered, regionally scale, there are only a few tests approximately the benefits of sharing financial system to a community. The painting created a business by allowing people to buy and sell electricity and demonstrate the advantages of distributing electricity. The maker assembled the issue in two strategies: peaceful and nonneighborhood location situated. In the communitarian approach, all occupants are endeavoring to develop the social authorities assist as opposed to being selfish, which is probably nonsensical to inhabitants; in the non-mixture process, where tenants are self-interested and venture to enhance their own income, which can also influence the Norm of the whole society. For any other paintings, it offers electricity to the chiefs and sharing method to decrease the pressure payments of occupants thru coordination of exceptional houses round there. Two forms of coordination approaches are gotten: \% primarily based totally and flip primarily based totally, and each treated the problem using inherited computation.

Nevertheless, those investigations fail to suggest PEV, which is the big problem of the cuttingedge evaluation paintings. All matters considered, those works stated to date labored efficiently in arranging the electricity buying and selling affiliation amongst occupants, but the better well worth of DSM, load reserving of own circle of relatives utilization, is dismissed, moreover it fails to recall viable pressure. As a result, the purpose of this work is to create a group DSM shape based on PEV that involves a financial sharing scheme and lowers both the rapid and challenging price and Standard. Despite this, many investigations had been concluded and, predictably, had surpassed expectations_(Sherif, Zhu, \& Lambotharan, 2014) _(Arul, Ravi, \& Sangoden, 2006).

The evaluation specific problem as a non-satisfactory recreation and exhibited a beautiful Nash balance. Another early review added production for an ideal association of battery charging/trade stations' motion structures and treated the problem through differential development computation. Despite the sole correction of the charging period, a pair of researchers also recall PV-assist, becoming a Vehicle to Cross segment member. The initial evenhanded regulator addressed the organization of charging impartial PEVs. The evaluation there identified the issue as an unsatisfactory recreation and displayed a lovely Nash balance. Methodology, or coping with the weakness. Nonetheless, those works regrettably left out the high-quality electricity looking after restriction of PEV, which may be applied to carry out load transferring.

Additionally, as opposed to preceding results, the paintings take a gander at using PEVs and PV structures in immense non-non-public structures for tops having and valley filling with inside the strength utilization profile to lessen Standard, besides the pressure price decline is not often considered. In this paper, the central notion is like, i.e., each wants to decrease the standard by load transferring capacity of PEV. However, our primary aim is to minimise power costs while making PEV activity more intentional, which is referred to as the low voltage charging situation that may impact battery lifestyles and defined as the compulsion to restrict the battery's SoC to stabilise itself. In addition, as the number of PEVs grows, the pressure mixture volume increases illogically for miles. The energy order type is therefore seen as a pressure duty to prevent excessive release _(Kim, Ren, van der Schaar, \& Lee, 2013)_(Celik, Roche, Bouquain, \& Miraoui, 2018).

\section{Future Scope}

In the future, there are several unique movements that you should consider. The fundamental goal of this survey is to concentrate on achieving a high degree of interchangeability in interest rates (Demand Response, Demand Side Management), as well as Distributed Generation, Electricity, and Smart Grids. Power is considered the primary means of building an intelligent network concept and optimizing massive power from renewable sources. Further, focus could be envisioned on an intelligent system for frequent clients on the exciting side, such as consumers searching for various dispersed fuel sources or energy-saving gadgets.

\section{Conclusion}


To summarise, End-clients seek to lower their financial energy costs by providing or saving energy rather than simply purchasing their energy demands on the network through a preimprovement rate operated by an independent-focused team. The DSM programs are investigated zone-wise along with meritorious phases and applications. The following matrix creation issue is planned as a non-interactive game in this paper, and the existence of good programs is investigated. Furthermore, distributed calculations on client-specific meters need to be implemented, which have better construction or collection strategies while ensuring customer protection and reducing the need for movement and concentration units. Finally, the proposed early development is put to the test under real-world conditions.

\section{Acknowledgement}

The authors are grateful to the authorities of VIT University, Chennai campus in order to carry out this research work in a prosperous manner.

\section{References:}

Arul, R., Ravi, G., \& Sangoden, V. (2006). Artifical Intelligent Solutions to Energy Management Problems. National conference on computational intelligence to emerging electric power systems. Puducherry, India: Pondicherry Engineering College.

Celik, B., Roche, R., Bouquain, D., \& Miraoui, A. (2018). Decentralized Neighborhood Energy Management With Coordinated Smart Home Energy Sharing. IEEE Transactions on Smart Grid, 9(6), 6387-6397. doi:10.1109/TSG.2017.2710358

Che, L., Shahidehpour, M., Alabdulwahab, A., \& Al-Turki, Y. (Noviembre de 2015). Hierarchical Coordination of a Community Microgrid With AC and DC Microgrids. IEEE Transactions on Smart Grid, 6(6), 3042-3051. doi:10.1109/TSG.2015.2398853

Cheng, P.-H., Huang, T.-H., Chien, Y.-W., Wu, C.-L., \& Fu, L.-C. (5-8 de Octubre de 2017).

Demand-side management in residential community realizing sharing economy with bidirectional PEV. 2017 IEEE International Conference on Systems, Man, and Cybernetics (SMC). Banff, AB, Canada: IEEE. doi:10.1109/SMC.2017.8122846

Hasib, A. A., Nikitin, N., \& Natvig, L. (2014). Load scheduling in smart buildings with bidirectional energy trading. IEEE 33rd International Performance Computing and Communications Conference (IPCCC). Austin, TX, USA: IEEE. doi:10.1109/PCCC.2014.7017039

Hsu, Y.-Y., \& Su, C.-C. (Agosto de 1991). Dispatch of direct load control using dynamic programming. IEEE Transactions on Power Systems, 6(3), 1056 - 1061. doi:10.1109/59.119246 Kamal, M., Assi, C., Maier, M., \& Uddin, M. (Enero de 2014). Smart Microgrids: Optimal Joint Scheduling for Electric Vehicles and Home Appliances. IEEE Transactions on Smart Grid, 5(1), 239250. doi:10.1109/TSG.2013.2290894

Kim, B.-G., Ren, S., van der Schaar, M., \& Lee, J.-W. (2013). Bidirectional Energy Trading and Residential Load Scheduling with Electric Vehicles in the Smart Grid. IEEE Journal on Selected Areas in Communications, 31(7), 1219-1234. doi:10.1109/JSAC.2013.130706

Kim, H.-M., Kinoshita, T., \& Shin, M.-C. (2010). A Multiagent System for Autonomous Operation of Islanded Microgrids Based on a Power Market Environment. Energies, 3(12), 1972-1990. doi:10.3390/en3121972

Kim, H.-M., Lim, Y., \& Kinoshita, T. (2012). An Intelligent Multiagent System for Autonomous Microgrid Operation. Energies, 5(9), 3347-3362. doi:10.3390/en5093347.

Kinhekar, N., Padhy, N. P., \& Gupta, H. O. (Febrero de 2014). Multiobjective demand side management solutions for utilities with peak demand deficit. International Journal of Electrical Power \& Energy Systems, 55, 612-619. doi:10.1016/i.ijepes.2013.10.011

Kuo, H.-H., Pradhan, S. K., Wu, C.-L., Cheng, P.-H., Xie, Y., \& Fu, L.-C. (2016). Dynamic demandside management with user's privacy concern in residential community. 2016 IEEE International Conference on Automation Science and Engineering (CASE). Fort Worth, TX, USA: IEEE. doi:10.1109/COASE.2016.7743526

Liu, Y., Yuen, C., Huang, S., Hassan, N. U., \& Wang, X. X. (Diciembre de 2014). Peak-to-Average Ratio Constrained Demand-Side Management With Consumer's Preference in Residential Smart Grid. IEEE Journal of Selected Topics in Signal Processing, 8(6), 1084-1097. 
Logenthiran, T., Srinivasan, D., \& Shun, T. Z. (Septiembre de 2012). Demand Side Management in Smart Grid Using Heuristic Optimization. IEEE Transactions on Smart Grid, 3(3), 1244-1252. doi:10.1109/TSG.2012.2195686

Moghaddam Arani, M. F., \& I. Mohamed, Y. A.-R. (Noviembre de 2018). Cooperative Control of Wind Power Generator and Electric Vehicles for Microgrid Primary Frequency Regulation. IEEE Transactions on Smart Grid, 9(6), 5677-5686. doi:10.1109/TSG.2017.2693992

Nguyen, D. T., \& Le, L. B. (Septiembre de 2014). Joint Optimization of Electric Vehicle and Home Energy Scheduling Considering User Comfort Preference. IEEE Transactions on Smart Grid, 5(1), 188-199. doi:10.1109/TSG.2013.2274521

Nikmehr, N., \& Ravadanegh, S. N. (Julio de 2015). Optimal Power Dispatch of Multi-Microgrids at Future Smart Distribution Grids. IEEE Transactions on Smart Grid, 6(4), 1648 - 1657.

doi:10.1109/TSG.2015.2396992

Nikmehr, N., \& Ravadanegh, S. N. (2016). Reliability evaluation of multi-microgrids considering optimal operation of small scale energy zones under load-generation uncertainties. International Journal of Electrical Power \& Energy Systems, 78, 80-87. doi:10.1016/j.ijepes.2015.11.094

Ogwumike, C., Short, M., \& Denai, M. (2015). Near-optimal scheduling of residential smart home appliances using heuristic approach. 2015 IEEE International Conference on Industrial Technology (ICIT). Seville, Spain: IEEE. doi:10.1109/ICIT.2015.7125560

Olivares, D. E., Cañizares, C. A., \& Kazerani, M. (2014). A Centralized Energy Management System for Isolated Microgrids. IEEE Transactions on Smart Grid, 5(4), 1864 - 1875.

doi:10.1109/TSG.2013.2294187

Peças Lopes, J. A., Soares, F. J., \& Rocha Almeida, P. M. (Enero de 2011). Integration of Electric Vehicles in the Electric Power System. Proceedings of the IEEE, 99(1), 168 - 183.

doi:10.1109/JPROC.2010.2066250

Sheikhi, A., Bahrami, S., \& Ranjbar, A. M. (2015). An autonomous demand response program for electricity and natural gas networks in smart energy hubs. Energy, 89, 490-499.

doi:10.1016/j.energy.2015.05.109

Sheikhi, A., Rayati, M., \& Ranjbar, A. (Julio de 2016). Dynamic load management for a residential customer; Reinforcement Learning approach. Sustainable Cities and Society, 24, 42-51.

doi:10.1016/j.scs.2016.04.001

Sheikhi, A., Rayati, M., Bahrami, S., \& Ranjbar, A. M. (9 de Enero de 2015). Integrated Demand Side Management Game in Smart Energy Hubs. IEEE Transactions on Smart Grid, 6(2), 675 - 683. doi:10.1109/TSG.2014.2377020

Sherif, H., Zhu, Z., \& Lambotharan, S. (2014). An optimization framework for home demand side management incorporating electric vehicles. 2014 IEEE Innovative Smart Grid Technologies - Asia (ISGT ASIA). Kuala Lumpur, Malaysia: IEEE. doi:10.1109/ISGT-Asia.2014.6873764 Song, N.-O., Lee, J.-H., Kim, H.-M., Im, Y. H., \& Lee, J. Y. (2015). Optimal Energy Management of Multi-Microgrids with Sequentially Coordinated Operations. Energies, 8(8), 8371-8390.

doi:10.3390/en8088371

Tian, P., Xiao, X., Wang, K. D., \& Ruoxing. (Septiembre de 2016). A Hierarchical Energy Management System Based on Hierarchical Optimization for Microgrid Community Economic Operation. IEEE Transactions on Smart Grid, 7(5), 2230-2241. doi:10.1109/TSG.2015.2470551

Tsikalakis, A. G., \& Hatziargyriou, N. D. (2011). Centralized control for optimizing microgrids operation. 2011 IEEE Power and Energy Society General Meeting. Detroit, MI, USA: IEEE.

doi:10.1109/PES.2011.6039737

Turker, H., Hably, A., \& Bacha, S. (2013). Housing peak shaving algorithm (HPSA) with plug-in hybrid electric vehicles (PHEVs): Vehicle-to-Home (V2H) and Vehicle-to-Grid (V2G) concepts. 4th International Conference on Power Engineering, Energy and Electrical Drives. Istanbul, Turkey: IEEE. doi:10.1109/PowerEng.2013.6635704

Wang, Y., Mao, S., \& Nelms, R. M. (Dicembre de 2015). On Hierarchical Power Scheduling for the Macrogrid and Cooperative Microgrids. IEEE Transactions on Industrial Informatics, 11(6), 15741584. doi:10.1109/TII.2015.2417496

Wang, Z., Chen, B., Wang, J., \& Chen, C. (Enero de 2016). Networked Microgrids for Self-Healing Power Systems. IEEE Transactions on Smart Grid, 7(1), 310-319. doi:10.1109/TSG.2015.2427513 Wang, Z., Chen, B., Wang, J., \& kim, J. (2016). Decentralized Energy Management System for Networked Microgrids in Grid-Connected and Islanded Modes. IEEE Transactions on Smart Grid, 7(2), 1097-1105. doi:10.1109/TSG.2015.2427371 
Zhang, F., Zhao, H., \& Hong, M. (Diciembre de 2015). Operation of networked microgrids in a distribution system. CSEE Journal of Power and Energy Systems, 1(4), 12-21.

doi:10.17775/CSEEJPES.2015.00043

Zhang, W., Chen, G., Su, Y., Dong, Z., \& Li, J. (2014). A dynamic game behavior: Demand side management based on utility maximization with renewable energy and storage integration. 2014 Australasian Universities Power Engineering Conference (AUPEC). Perth, WA, Australia: IEEE. doi:10.1109/AUPEC.2014.6966581

Zhu, Z., Tang, J., Lambotharan, S., Chin, W. H., \& Fan, Z. (16-20 de Enero de 2012). An integer linear programming based optimization for home demand-side management in smart grid. 2012 IEEE PES Innovative Smart Grid Technologies (ISGT). Washington, DC, USA: IEEE. doi:10.1109/ISGT.2012.6175785

Zou, N., Qian, L., Attia, J., \& Xie, L. (2012). Optimization of Home Energy Usage by Intelligently Charging/Discharging EV/PHEV. 2012 International Conference on Connected Vehicles and Expo (ICCVE). Beijing, China: IEEE. doi:10.1109/ICCVE.2012.70

(C) 2020 by the authors. Licensee TESEA, Cartagena, Colombia. This article is an open access article distributed under the terms and conditions of the Creative Commons Attribution (CC BY) license (http:/ / creativecommons.org/licenses/by/4.0/). 